\title{
Directed Technological Change: A Knowledge-Based Model*
}

\author{
Shiyuan $\operatorname{Pan}^{\dagger} \quad$ Heng-fu Zou ${ }^{\ddagger}$ Tailong $\mathrm{Li}^{\S}$
}

\begin{abstract}
We develop a knowledge-based growth model to address the issues of directed technological change, wage inequality and economic growth, in which skilled workers are used both in innovation and production. Since skill-biased technological change may lead to a decrease in the average productivity in R\&D sectors, scale effect is removed. Free trade between developed countries increases the demand for skilled workers employed in the production of the skill-intensive good, thus promoting skill-biased technological change through the market size effect and an increase in skill premia. In contrast, free trade between developed and developing countries reduces the profits of skill-complementary innovation, since its market is relatively small in the developing country. Thus, international trade may lead to skill-replacing technological change and decrease wage inequality in the developed country. Wage inequality, however, increases in the developing countries since the degree of skill bias of technology in the developing country in the open economy is greater than the one in autarky. Skill-biased technological change has opposite effects on economic growth, therefore trade stimulates economic growth in some circumstances, and hurts it in other circumstances.
\end{abstract}

Keywords: Directed Technological Change; Wage Inequality; Scale Effect; Trade; Growth

JEL Classification: E25; J31; O30; O31; O33

\footnotetext{
*We thank Daron Acemoglu, Koichi Hamada, Yosuke Takeda and Masaya Sakuragawa and seminar participants at Chincese University of Hongkong for helpful comments. All errors are ours.

${ }^{\dagger}$ Corresponding Author. Center for Research of Private Economy and School of Economics, Zhejiang University, 38 Zheda Road, Hangzhou 310027, P.R.China. E-mail Address: shiyuanpan@zju.edu.cn. Phone Number: 86-13957118355. Fax Number: 86-571-87952835.

${ }^{\ddagger}$ Central University of Finance and Economics CEMA, 39 South College Road, Haidian District, Beijing 100081, P.R.China. E-mail Address: zouhengfu@gmail.com.

$\S$ School of Economics \& Management, Zhejiang Sci-Tech University, West District, Xiasha Higher Education Zone, Hangzhou 310018, P.R. China. E-mail Address: m9845@163.com.
} 


\section{Motivation}

Many knowledge-based growth models imply that there exists scale effect, that is, the growth rate rises with total population or the employment of scientists and engineers. The data, however, is against this theoretical implication. For example, figure 1 in Jones (1995a) reports that, despite a substantial increase in the amount of labor engaged in $R \& D$, there has not been any upward trend in many OECD countries for the postwar period. Moreover, figures 2 and 3 in Laincz and Peretto (2006) show that the productivity growth rate remains roughly unchanged, even though the total personnel and R\&D personnel raise in the United States. In the meantime, since the relative supply of skilled workers goes up sharply after World War $\mathrm{II}^{1}$, technological change is towards skills. Acemoglu (2002b) states that, assuming the elasticity of substitution between skilled and unskilled workers to be 1.4, the degree of skill bias of technology was approximately 0.030 in 1960, became 0.069 and 0.157 in 1970 and 1980, respectively, increased to 0.470 in 1990.

Acemoglu (2009, Ch. 15) tries to build a knowledge-based model of directed technological change to remove scale effect. However, Acemoglu's model assumes that the total amount of scientists employed in R\&D sectors is given exogenously. Indeed, how many scientists are employed must be an equilibrium allocation of skilled workers between production and innovation. In other words, Acemoglu's model is not a real knowledge-based one in the sense that skilled workers are not allocated between production and innovation. Moreover, one implication of Acemoglu's model is that the economic growth rate depends on the growth rate of the population of scientists. Finally, the relationship between skill-biased technological change and scale effect is ignored in Acemoglu's model. Hence, the first goal of this paper is to develop a model to account for the above two facts, accelerated skill-biased technological change and the absence of scale effect.

The existing models of directed technological change mainly focus on the effect of trade between developed and developing countries on skill premia (for example, Acemoglu, 2003a, 2009, Theonig and Verdier, 2003). They disregard the effect of trade between developed countries (regions) on skill premia. As a matter of fact, numerous studies document that trade in intermediate goods between developed countries or regions has grown substantially in the last decades (e.g., Krugman, 1995, 2000, Feenstra and Hanson, 1996, Feenstra, 1998). Furthermore, to a great extent, they also neglect the impact of trade on economic growth. In Acemoglu (2003a) free trade will not change the growth rate of developed countries. Therefore, the second goal of this paper is to investigate the effect of trade on world growth and skill premia.

\footnotetext{
${ }^{1}$ Autor et al (1998) have reported that on average the supply of skills has grown 3.06 percent a year during 1970 and 1995, while it has raised 2.63 percent a year between 1940 and 1970 .
} 
The plan of the rest of the paper is as follows. In section 2, we review the related literature. Section 3 presents the basic model, building on Rivera-Batiz and Romer (1991) and Acemoglu (1998, 2002a, 2003a, 2007, 2009). The key assumption is that knowledge and skilled workers are the only inputs for innovation. In Section 4, we apply the basic model to address the issues of the direction of technological change, scale effect and skill premia. Section 5 extends the basic model to illustrate the impact of international trade on wage inequality and economic growth. Some conclusions are contained in Section 6.

\section{Related Literature}

In the last decade there was a flourishing controversy about scale effect. Does a large economy grow faster? The answer from the first-generation knowledge-based growth models is yes (Romer, 1990, Grossman and Helpman, 1991, Aghion and Howitt, 1992). But the empirical analysis has questioned the validity of scale effect. As a result, the second-generation models have been proposed to remove scale effect. These models exhibit semi-endogenous growth, i.e., technological change is endogenous in the sense that it requires real resources, as do the first-generation models, but the long-run growth is exogenous and proportional to the rate of population growth as in the neo-classical growth models (Jones, 1995a, 1995b, Kortum, 1997, Segerstrom, 1998, Acemoglu, 2009). The result that exponential growth depends on population growth is sufficiently at odds with the spirit of the endogenous growth literature, hence the third-generation models have been put forward to eliminate scale effect while the endogeneity of the steady state growth rate is preserved (Young, 1998, Peretto, 1998, Aghion and Howitt, 1998, Dinopoulos and Thompson, 1998). ${ }^{2}$

Many of the existing models have not considered the direction of technological change, and Acemoglu (1998, 2001, 2002a, 2003a, 2009) has made a serious effort to study whether or not technological change is biased towards particular factors. This paper explores the relationship between skill-biased technological change and scale effect. First, skill-biased technological change has a negative effect on the growth rate by reducing the average productivity of skill-complementary knowledge in the R\&D sector, which creates innovation complementing skilled workers. Second, it has a positive effect on the growth rate by raising the average productivity of labor-complementary knowledge in the $\mathrm{R} \& \mathrm{D}$ sector, which generates knowledge complementing unskilled workers. Therefore, when the amount of skilled workers increases, the growth rate remains unchanged if the two competing effects exactly offset each other, and the growth rate decreases if the former effect is powerful.

\footnotetext{
${ }^{2}$ See Jones $(1999,2005)$ for further theoretical and empirical references.
} 
To our knowledge, this paper is the first to explain these two phenomena, accelerated skill-biased technological change and the absence of scale effect in a unified framework.

This paper shows that increased international trade between developed countries could be a major cause of rising wage inequality because it induces skill-biased technological change. ${ }^{3}$ Acemoglu (2003a) and Theonig and Verdier (2003), among others, show that international trade between a developed and developing country increases wage inequality by leading to technological change towards skilled workers. In Acemoglu's paper, it is trade in the final good that leads to the relative price of the skill-intensive good go up, thus encouraging technological change towards skilled workers and increasing skill premia. Thoenig and Verdier (2003) show that free trade causes knowledge diffusion and extends the possibilities of imitation, hence inducing firms to adopt defensive innovation strategies to reinforce non-replication measures. This strategy leads to an increment in the relative demand for skills, thus raising skill premia. Unlike in the existing papers, the main mechanism in this paper is that international trade between developed countries increases the amount of skilled workers used in the production of the skill-intensive good, hence resulting a large market size for skill-complementary technology. As a consequence, international trade encourages skill-biased technological change and an increase in wage inequality.

Furthermore, our paper shows that since the market of skill-complementary technology in the developing country is relatively small, trade opening reduces the relative profits of skill-complementary technology. Consequently, technological change may be skill-replacing and wage inequality in the developed country declines. This result is different from the one in Acemoglu (2003a) and Theonig and Verdier (2003). Moreover, the degree of skill bias of technology in the open economy is greater than that in the developing country before opening, since the developed country is skill-abundant. Therefore, open trade leads to an increase in wage inequality in the developing country.

Since open trade between developed countries encourages technological change towards skilled workers, it promotes economic growth when the positive effect of skill-biased technological change on the growth rate is powerful. Yet open trade hurts economic growth when the negative effect of skill-biased technological change on the growth rate is dominant. Similarly, open trade between developed and de-

\footnotetext{
${ }^{3}$ A number of empirical studies have reported a substantial increase in skill premia, while the supply of skills was rising rapidly in most developed countries during last decades. In response to these studies, the theoretical literature has stressed two main explanations: increased international trade and skill-biased technological change (see Aghion, Carloli and Garcí-Peñalosa, 1999, Acemoglu, 2002b, Hornstein, Krusell and Violante, 2005). Most economists argue it is likely that skill-biased technological change plays a more important role than international trade. In other words, they state that if the introduction of new technology increases the demand for skilled workers, then wage inequality will likely increase during the period of economic development (Katz and Murphy, 1992, Krusell, Rios-Rull and Violante, 2000, Acemoglu, 1998, 2002a, 2003a).
} 
veloping country would also not increase the world growth rate. This implies that trade opening does not always stimulate economic growth, even though it enhances the opportunities of (developing) countries to access advanced technology. This result is different from the one in the existing studies (e.g., Rivera-Batiz and Romer, 1991), which shows that trade with flows of ideas can permanently increase the rate of growth.

There are three forces determining the direction of technological change: (1) the price effect, which creates incentives to develop unskill-biased (skill-replacing) technology when the amount of skilled workers is big; (2) the market size effect, which induces the development of skill-biased technology when the quantity of skilled workers is large; and (3) the effect of innovation possibilities frontier, which encourages the development of future skill-complementary (labor-complementary) technology when technological change today is biased towards labor (skills). The elasticity of substitution between the factors, skilled and unskilled workers, determines the relative strengths of the former two competing effects. The bigger the elasticity of substitution, the more powerful the market size effect. At the same time, the effect of innovation possibilities frontier increases with the degree of state-dependence. ${ }^{4}$

We show that when the elasticity of substitution between skilled and unskilled workers is sufficiently large and the degree of state-dependence is small enough, technological change is skill-biased. In the meantime, since an increase in the amount of skilled workers increases the relative wages of unskilled workers by raising the relative price of the labor-intensive good, skill-biased technological change does not favor skilled workers absolutely. Skill premia increase only if the elasticity of substitution is sufficiently great. These results of the direction of technological change and skill premia look similar to those in Acemoglu (2002a). However, our framework is different from that in Acemoglu's. In our model, the knowledge accumulation equation is a knowledge-based specification, in which skilled workers and knowledge are the only inputs generating new innovation. Acemoglu's model, on the other hand, uses a lab-equipment specification, in which only the final good is used in generating new knowledge. ${ }^{5}$

\section{The Model}

In this section, we outline the basic model. The key assumption is that skilled workers are used both in innovation and in consumer goods production.

\footnotetext{
${ }^{4}$ The degree of state-dependence measures the spillover effect of one type of technology on the production of another one. See Acemoglu (2002a) for the definition.

${ }^{5}$ See River-Batiz and Romer (1991) for the discussion of the two specifications.
} 


\subsection{The Environment}

We consider a close economy populated $H$ skilled workers and $L$ unskilled workers. Representative consumers have constant relative risk aversion (CRRA) preferences. At time 0, these consumers seek to maximize

$$
\int_{0}^{\infty} \frac{C(t)^{1-\theta}-1}{1-\theta} e^{-\rho t} d t
$$

where $C(t)$ is consumption at time $t, \theta$ is the coefficient of the intertemporal elasticity of substitution, and $\rho$ is the discount rate. We suppress time index for simplicity.

Maximization of utility, subject to a standard budget constraint, yields the usual formula for the growth rate of consumption:

$$
\frac{\dot{C}}{C}=\frac{1}{\theta}(r-\rho),
$$

where $r$ is the rental price of capital. Equation (2) says that the larger the intertemporal elasticity of substitution, the higher the rate of consumption growth; and that the greater the discount rate, the lower the rate of consumption growth.

Aggregate output is defined over a constant elasticity of substitution (CES) aggregate of a skill-intensive and a labor-intensive good. More formally, aggregate output is given by

$$
Y=\left[\left(Y_{l}\right)^{\frac{\epsilon-1}{\epsilon}}+\left(Y_{h}\right)^{\frac{\epsilon-1}{\epsilon}}\right]^{\frac{\epsilon}{\epsilon-1}},
$$

where $Y_{l}$ is the total output of the labor-intensive good, $Y_{h}$ is the total output of the skill-intensive good, and parameter $\epsilon \in[0, \infty)$ is the elasticity of substitution between the two goods. When $\epsilon=\infty$, the two goods are perfect substitutes, and the function is linear. When $\epsilon=1$, the function is Cobb-Douglas. And when $\epsilon=0$, there is no substitution between the two goods, and the production function is Leontieff.

The market for the two goods is competitive, hence market clearing implies that the relative price of the skill-intensive good is:

$$
p=\frac{p_{h}}{p_{l}}=\left(\frac{Y_{h}}{Y_{l}}\right)^{-\frac{1}{\epsilon}}
$$

where $p_{h}$ and $p_{l}$ are the prices of the skill-intensive and the labor-intensive good, respectively. We choose the price of the final good as the numeraire.

The skill-intensive good is produced by skilled workers and different types of intermediate goods, whereas the labor-intensive good is produced by unskilled 
workers and a set of differentiated intermediates. For simplicity, suppose some intermediate goods are skill-complementary, while other intermediate goods are labor-complementary. Specifically, the production functions of the skill-intensive and the labor-intensive good are given respectively by:

$$
Y_{h}=\int_{0}^{A_{h}}\left(k_{h}(i)\right)^{1-\alpha} d i \cdot H_{Y}^{\alpha},
$$

and

$$
Y_{l}=\int_{0}^{A_{l}}\left(k_{l}(i)\right)^{1-\alpha} d i \cdot L^{\alpha}
$$

where $0<\alpha<1, A_{z}$ is the varieties of intermediate goods complementary to workers of skill level $z, k_{z}(i)$ is the quantity used of intermediate good $i$ together with workers of skill level $z, z=h, l$. Indexes $h$ and $l$ denote skilled and unskilled workers, respectively. $H_{Y}$ is the amount of skilled workers employed in the production of the skill-intensive good, $L$ is the amount of unskilled workers used in the production of the labor-intensive good. The assumption that different intermediate goods are employed to produce different goods allows technological change to be biased. The production functions in (5) and (6) exhibit constant returns to scale in inputs: a double of labor and the quantities of all intermediate goods doubles output. However, the production possibilities set of the economy will exhibit increasing returns to scale because technological knowledge, $A_{z}$, will be determined endogenously.

The innovation possibilities frontier takes the form of knowledge-based R\&D specification. Formally, the production functions for the variety of new machines are given respectively by

$$
\dot{A}_{h}=\left(A_{h}\right)^{\frac{1+\delta}{2}}\left(A_{l}\right)^{\frac{1-\delta}{2}} H_{h} \text { and } \dot{A}_{l}=\left(A_{h}\right)^{\frac{1-\delta}{2}}\left(A_{l}\right)^{\frac{1+\delta}{2}} H_{l},
$$

where $H_{z}$ is the quantity of skilled workers employed in generating knowledge complementary to workers of skill level $z .{ }^{6}$ Equation (7) says that R\&D activity is more skill-intensive than consumer goods production. As Acemoglu (2002a), $\delta \leq 1$ measures the degree of state-dependence. When $\delta=0$, there is no state-dependence, because both $A_{h}$ and $A_{l}$ create spillovers for research in both sectors. In contrast, when $\delta=1$, there is an extremely large amount of state-dependence, since $A_{h}$ and $A_{l}$ only cause spillovers for skill-complementary and labor-complementary innovation, respectively. The main difference between our model and Acemoglu's is whether R\&D sectors use skilled workers or not.

\footnotetext{
${ }^{6}$ The existing studies give attention to the relationship between the number of scientists and economic growth. Therefore, we assume that, in this paper, R\&D sectors only employ skilled workers. Of course, we can alternatively assume that R\&D sectors employ unskilled workers or a combination of skilled and unskilled workers. Due to space limits, we leave out the discussion.
} 


\subsection{Equilibrium}

We now characterize the economic equilibrium in this economy. As a price taker, producers of the skill-intensive and the labor-intensive good maximize profits by taking the prices of the two goods, wages, and the rental prices of intermediate goods as given. This maximization results in the demand for intermediate good $i$ complementary to skilled and unskilled workers:

$$
k_{h}(i)=\left[(1-\alpha) \cdot p_{h} / \chi_{h}(i)\right]^{1 / \alpha} \cdot H_{Y},
$$

and

$$
k_{l}(i)=\left[(1-\alpha) \cdot p_{l} / \chi_{l}(i)\right]^{1 / \alpha} \cdot L,
$$

where $\chi_{z}(i)$ is the price of intermediate goods. For convenience and without loss of generality, suppose the marginal cost for the production of any intermediate good is $\eta=(1-\alpha)^{2}$ units of the final good. Producers of intermediate good $i$ choose a level of output $k_{z}(i)$ to maximize profits

$$
\pi_{z}(i)=\max _{k_{z}(i)} \chi_{z}(i) k_{z}(i)-\eta k_{z}(i) .
$$

The revenue is $\chi_{z}(i)$ times $k_{z}(i)$, and the total cost is $\eta k_{z}(i)$ units of the final good.

The maximization of profits gives the monopoly price:

$$
\chi_{z}(i)=\chi_{z}=1-\alpha,
$$

which is the same at all points in time and for all types of intermediates. Therefore, substitution of (11) into (8) and (9) yields the demand for intermediate good $i$ used by workers of skill level $h$ and $l$ :

$$
k_{h}=k_{h}(i)=\left(p_{h}\right)^{1 / \alpha} \cdot H_{Y},
$$

and

$$
k_{l}=k_{l}(i)=\left(p_{l}\right)^{1 / \alpha} \cdot L .
$$

Therefore, the monopoly profits of any intermediate good used by skilled and unskilled workers at time $\tau$ are respectively

$$
\pi_{h}(\tau)=\alpha(1-\alpha)\left[p_{h}(\tau)\right]^{1 / \alpha} \cdot H_{Y}
$$

and 


$$
\pi_{l}(\tau)=\alpha(1-\alpha)\left[p_{l}(\tau)\right]^{1 / \alpha} \cdot L .
$$

Substituting (12) and (13) into (5) and (6), respectively, we obtain

$$
Y_{h}=\left(p_{h}\right)^{(1-\alpha) / \alpha} \cdot A_{h} H_{Y} \text { and } Y_{l}=\left(p_{l}\right)^{(1-\alpha) / \alpha} \cdot A_{l} L .
$$

Inspection of (4) and (16) reveals that the relative price of the skill-intensive and the labor-intensive good is

$$
p=\frac{p_{h}}{p_{l}}=\left(\frac{A_{h}}{A_{l}} \cdot \frac{H_{Y}}{L}\right)^{-\frac{\alpha}{1+\alpha(\epsilon-1)}} .
$$

This shows that when either the technology is highly skill-biased (high $A_{h} / A_{l}$ ) or the relative amount of skilled workers employed in the production of the skillintensive good is large (high $H_{Y} / L$ ), the relative supply of the skill-intensive good is large and the relative price is low.

If there is free entry into the $R \& D$ business and if the equilibrium quantity of skilled workers employed in $\mathrm{R} \& \mathrm{D}$ sectors is nonzero at all points in time, then the price for knowledge will be bid up until it is equal to the present value of the monopoly profits seized by a producer of intermediates. This condition implies

$$
P_{z}(t)=\int_{t}^{\infty} e^{-\int_{t}^{\tau} r(s) d s} \pi_{z}(\tau) d \tau
$$

where $P_{z}(t)$ is the price for knowledge. If $P_{z}(t)$ is constant (as it will be in the equilibrium characterized below), the condition can be rewritten as a more intuitive form. Differentiating with respect to time $t$ results in

$$
\pi_{z}(t)=r(t) \int_{t}^{\infty} e^{-\int_{t}^{\tau} r(s) d s} \pi_{z}(\tau) d \tau
$$

Combination of (18) and (19) leads to

$$
r(t)=\frac{\pi_{z}(t)}{P_{z}(t)}
$$

This equation says that the interest rate, $r(t)$, is the ratio of the monopoly profits flow, $\pi_{z}(t)$, to the lump-sum cost on the initial investment in discovering a new design for a type of intermediate good. Equations (14), (15) and (20) suggest that the prices of skill- and labor- complementary knowledge are respectively

$$
P_{h}=\alpha(1-\alpha)\left(p_{h}\right)^{1 / \alpha} \cdot H_{Y} / r \text { and } P_{l}=\alpha(1-\alpha)\left(p_{l}\right)^{1 / \alpha} \cdot L / r .
$$

The wages paid in the skill-intensive good sector are 


$$
w_{h}=\alpha\left(p_{h}\right)^{1 / \alpha} \cdot A_{h} .
$$

In the meantime, inspection of (7) and (21) yields the wages paid in R\&D sectors:

$$
w_{h}=P_{h} \cdot\left(A_{h}\right)^{\frac{1+\delta}{2}}\left(A_{l}\right)^{\frac{1-\delta}{2}}=P_{l} \cdot\left(A_{h}\right)^{\frac{1-\delta}{2}}\left(A_{l}\right)^{\frac{1+\delta}{2}} .
$$

Skilled workers are employed to produce the skill-intensive good and knowledge, thus the equilibrium wages paid in the skill-intensive good sector and R\&D sectors must be equated. Combining (21), (22) and (23), we get

$$
H_{Y}=\frac{r\left(A_{h} / A_{l}\right)^{\frac{1-\delta}{2}}}{1-\alpha} .
$$

This shows that labor and capital is substituted, if the rental price of capital rises, then the firm employs more labor and less capital, and vice versa. Since $A_{h} / A_{l}$ determines the relative productivity of skilled and unskilled workers, producers of the skill-intensive good increase the demand for skilled workers as $A_{h} / A_{l}$ increases.

In the balanced growth path (BGP), the number of skill-complementary intermediate goods and that of labor-complementary intermediate goods have the same growth rate. Therefore, (7) suggests

$$
\left(A_{h} / A_{l}\right)^{\delta-1} H_{h}=H_{l} .
$$

Meanwhile, output, consumption and the number of intermediate goods grow at the same rate in BGP. Using (2), (24) and (25), we obtain

$$
H_{Y}=\frac{\theta H+\rho\left(A_{h} / A_{l}\right)^{\frac{1-\delta}{2}}\left[1+\left(A_{h} / A_{l}\right)^{\delta-1}\right]}{\theta+(1-\alpha)\left[1+\left(A_{h} / A_{l}\right)^{\delta-1}\right]} .
$$

Obviously, (26) is the result of skilled wage equalization in production and innovation which also takes into account the steady-state growth rate determined by the allocation of skilled workers to production and innovation. In order to obtain the equilibrium growth rate, it is useful to know the value of $A_{h} / A_{l}$. For this purpose, let us combine (17), (21) and (23). This gives

$$
\frac{A_{h}}{A_{l}}=\left(\frac{H_{Y}}{L}\right)^{\frac{1}{\lambda}}
$$

where $\lambda=\frac{1-\delta[1+\alpha(\epsilon-1)]}{\alpha(\epsilon-1)}$. Clearly, (27) comes from equalization of skilled wages in the innovation of skill- and labor- complementary knowledge which also takes into account the equilibrium in the product market. Taking advantage of (26) and (27), we obtain 
$f\left(\frac{A_{h}}{A_{l}}\right)=L\left(\frac{A_{h}}{A_{l}}\right)^{\lambda}\left\{\theta+(1-\alpha)\left[1+\left(\frac{A_{h}}{A_{l}}\right)^{\delta-1}\right]\right\}-\rho\left(\frac{A_{h}}{A_{l}}\right)^{\frac{1-\delta}{2}}\left[1+\left(\frac{A_{h}}{A_{l}}\right)^{\delta-1}\right]-\theta H=0$,

The existence of a solution to (28) is easily proven (see the Appendix). Apparently, there may exist more than one solution to $(28) .{ }^{7}$ Let $\left(\frac{A_{h}}{A_{l}}\right)_{1}, \cdots,\left(\frac{A_{h}}{A_{l}}\right)_{I}, I \geq 1$, denote the solutions. For simplicity, suppose $\left(\frac{A_{h}}{A_{l}}\right)_{i}>\left(\frac{A_{h}}{A_{l}}\right)_{j}$ as $i>j$.

If the dynamic path of this economy can be described precisely, we can show which solution maximizes the utility. Unfortunately, the dynamics are so complicated that it is impossible to do this. In most cases, an increase in the growth rate increases social welfare. ${ }^{8}$ Therefore, it is reasonable to let the degree of skill bias of technology maximizing the growth rate be a unique equilibrium. ${ }^{9}$ Hence, by (24) and (27), we obtain the equilibrium growth rate

$$
g^{*}=\frac{(1-\alpha) L\left[\left(\frac{A_{h}}{A_{l}}\right)^{*}\right]^{\frac{2 \lambda+\delta-1}{2}}-\rho}{\theta},
$$

where $\left(\frac{A_{h}}{A_{l}}\right)^{*}=\left(\frac{A_{h}}{A_{l}}\right)_{I}$ as $\lambda>\frac{1-\delta}{2} ;\left(\frac{A_{h}}{A_{l}}\right)^{*}=\left(\frac{A_{h}}{A_{l}}\right)_{1}$ when $\lambda<\frac{1-\delta}{2} ;\left(\frac{A_{h}}{A_{l}}\right)^{*}=\left(\frac{A_{h}}{A_{l}}\right)_{i}$ while $\lambda=\frac{1-\delta}{2}$. The growth rate expression suggests that the parameters must be assumed to be such that $g^{*} \geq 0$. Otherwise, the constraint that $A_{z}$ cannot be decreasing would be violated, and the free-entry condition for R\&D would not hold with equality.

We now investigate the stability of the equilibrium. Combining (17), (21) and $(27)$, we obtain that $\frac{\partial\left(P_{h} \cdot\left(A_{h}\right)^{\frac{1+\delta}{2}}\left(A_{l}\right)^{\frac{1-\delta}{2}} / P_{l} \cdot\left(A_{h}\right)^{\frac{1-\delta}{2}}\left(A_{l}\right)^{\frac{1+\delta}{2}}\right)}{\partial\left(\frac{A_{h}}{A_{l}}\right)}<0$ when $\delta<\frac{1}{1+\alpha(\epsilon-1)}$. Therefore, when $\delta<\frac{1}{1+\alpha(\epsilon-1)}$, equilibrium dynamics are stable. On the contrary, when $\delta>\frac{1}{1+\alpha(\epsilon-1)}$, the equilibrium is unstable and will take us to a corner solution where only one type of $R \& D$ is undertaken. Thus, in the following analysis, we restrict our attention to the case where $\delta<\frac{1}{1+\alpha(\epsilon-1)}$ is satisfied.

Furthermore, by (3), (16) and (17), we know that the elasticity of substitution between the two factors, skilled and unskilled workers, is $1+\alpha(\epsilon-1)$. The elasticity of substitution is generally difficult to estimate, but there is a relatively widespread consensus that it is greater than 1, most likely, greater than 1.4, and perhaps as large as $2 .{ }^{10}$ Hence, we take $\epsilon>1$ in the rest of the paper.

\footnotetext{
${ }^{7}$ Obviously, under some circumstances (e.g., when $\left.\delta=1\right)$, (28) has only a single solution. See the Appendix for further details.

${ }^{8}$ High growth rate does not increase social welfare when economic growth causes large negative external effects.

${ }^{9}$ Indeed, the main results are independent of which degree of skill bias of technology is used in the following analysis.

${ }^{10}$ See Acemoglu (2002b) for further references.
} 


\section{Applications}

In this section, we apply the model to address the issues of directed technological change, scale effect and wage inequality.

\subsection{Directed Technological Change}

Using (21), we obtain the relative profitability of innovating technology complementary to skilled and unskilled workers is:

$$
\begin{aligned}
& \frac{P_{h}}{P_{l}}=\underbrace{p^{\frac{1}{\alpha}}} \cdot \underbrace{\frac{H_{Y}}{L}} . \\
& \text { price market } \\
& \text { effect size effect }
\end{aligned}
$$

This expression shows that the relative profitability of the two types of innovation is determined by the price effect and the market size effect. Clearly, the more the amount of skilled workers used in the production of the skill-intensive good, the lower the relative price of the good. Therefore, other things being equal, the relative profitability of the two types of innovation declines with the quantity of skilled workers used in the production of the skill-intensive good via the price effect. Equations (8) and (9) imply that the relative demand for skillcomplementary intermediates increases with the amount of skilled workers. It is followed that the more the quantity of skilled workers, the larger the relative profits of skill-complementary intermediates. Hence, other things being equal, the relative profitability of the two types of innovation rises with the quantity of skilled workers used in the production of the skill-intensive good via the market effect.

In the meantime, taking advantage of (23), we find

$$
\begin{aligned}
\frac{P_{h}}{P_{l}}= & \underbrace{\left(\frac{A_{h}}{A_{l}}\right)^{-\delta}}_{\begin{array}{l}
\text { effect of innovation } \\
\text { possibilities frontier }
\end{array}} \cdot
\end{aligned}
$$

This says that the effect of innovation possibilities frontier reduces the relative profits of future technology complementing skilled or unskilled workers, when technological change today is skill-biased or unskill-biased. Equation (7) shows that skill-biased technological change declines the average productivity of $A_{h}$ in the R\&D sector which generates knowledge complementary to skilled workers, while 
it increases the average productivity of $A_{l}$ in the $\mathrm{R} \& \mathrm{D}$ sector which generates knowledge complementary to unskilled workers. Therefore, the relative profits of future skill-complementary technology decreases when technological change today is biased towards skills.

The greater the profitability of innovation, the more the innovation. Therefore, (30) and (31) reveal that the direction of technological change depends on three strengths: the price effect, the market size effect and the effect of innovation possibilities frontier.

We now address the issue of directed technological change. If the relationship between $H_{Y}$ and $H$ is known, then by using (27), we can easily address the issue of directed technological change. Intuitively, we know ${ }^{11}$

$$
\frac{\partial\left(H_{Y} / L\right)}{\partial(H / L)}>0,
$$

i.e., the more the relative amount of skilled workers, the more the relative quantity of skilled workers employed in the skill-intensive good sector. Therefore, combining (27) and (32), we state the following proposition.

Proposition 1 When $\epsilon>1$ and $\delta<\frac{1}{1+\alpha(\epsilon-1)}$, technological change is skill-biased.

Proof. See the Appendix.

The intuition is straightforward. The greater the profitability of innovation, the more the innovation. Therefore, (30) and (31) reveal that the direction of technological change depends on three strengths: the price effect, the market size effect and the effect of innovation possibilities frontier. An increase in the amount of skilled workers enlarges $\frac{H_{Y}}{L}$, thus encouraging technological change towards skilled workers. In contrast, it induces skill-replacing technological change by decreasing the relative price of the skill-intensive good, $p$. Clearly, when $\epsilon>1$ and $\delta<\frac{1}{1+\alpha(\epsilon-1)}$, the market size effect is relatively powerful, the price effect and the effect of innovation possibilities frontier are sufficiently weak. As a result, technological change is towards skilled workers. Thus, like Acemoglu (2002a), our knowledge-based model can provide a possible interpretation for why technological change over the past 60 years was skill-biased, for why the skill bias may have accelerated over the past twenty-five years and for why new technology introduced during the late eighteenth and early nineteenth centuries was unskill-biased.

\subsection{Scale Effect}

The first-generation knowledge-based growth models suggest that a large economy grows fast (Romer, 1990, Grossman and Helpman, 1991, Aghion and Howitt, 1992).

\footnotetext{
${ }^{11}$ See proof in the Appendix.
} 
However, a large number of empirical studies have shown that scale effect is absent in the postwar period - i.e., the growth rate exhibits no large persistent change, while the amount of skilled workers employed in R\&D sectors increases largely. Therefore, a lot of models have been developed to remove scale effect on the growth rate (see, for example, Jones, 1995, Kortum, 1997, Young, 1998, Peretto, 1998, Aghion and Howitt, 1998, Peretto and Smulders, 2002, Acemoglu, 2009). In these papers, one mechanism behind the story of the absence of scale effect is the decreasing returns to knowledge, whereas another mechanism is that the entry of new firms perfectly dilutes the larger rent for innovation originating from a larger market. We would like to provide a new insight here as to why scale effect might be removed.

Using (29), we state the following proposition

Proposition 2 Suppose $\epsilon>1$ and $\delta<\frac{1}{1+\alpha(\epsilon-1)}$. When $\lambda=\frac{1-\delta}{2}$, the growth rate is unrelated to the amount of skilled workers, i.e., $\frac{\partial g^{*}}{\partial H}=0$. While $\lambda<\frac{1-\delta}{2}$, the growth rate decreases with the amount of skilled workers, i.e., $\frac{\partial g^{*}}{\partial H}<0 .{ }^{12}$

Proof. See the Appendix.

Let us recall (7). On the one hand, skill-biased technological change decreases the average productivity of $A_{h}$ in the R\&D sector, which generates knowledge complementary to skilled workers, hence the growth rate declines. On the other hand, it increases the average productivity of $A_{l}$ in the R\&D sector, which creates knowledge complementing unskilled workers. Thus the growth rate raises. ${ }^{13}$ Therefore, when the quantity of skilled workers goes up, the growth rate remains unchanged if the two competing forces exactly offset each other, and the growth rate decreases if the former force is powerful. ${ }^{14}$

It is argued here that, since skill-biased technological change decreases the average productivity in $\mathrm{R} \& \mathrm{D}$ sectors, the growth rate remains invariant or declines in the postwar period in the United States, even though the number of scientists grows. Hence, the mechanism behind the story of the absence of scale effect in this paper is different from that in the existing literature.

Indeed, even though the increase in the amount of unskilled workers is taken

\footnotetext{
${ }^{12}$ Since empirical studies document that the increase in the amount of scientists does not lead to high economic growth, we only focus on the effect of the amount of skilled workers on the growth rate.

${ }^{13}$ Unskill-biased technological change increases the average productivity of $A_{h}$ in the R\&D sector, which produces skill-complementary knowledge, and decreases the average productivity of $A_{h}$ in the R\&D sector, which generates labor-complementary knowledge. Therefore, a large economy also may not grow fast when technological change is unskill-biased.

${ }^{14}$ Grossman and Helpman (1991) discuss the relationship between the size of the economy and the growth rate. They show that an expansion in the factor used most intensively in the R\&D sector necessarily speeds innovation and growth, but an expansion of the factor used least intensively in this activity slows down growth. Therefore, an increases in the stock of human capital increases the growth rate, whereas the growth rate decreases with the increases in the amount of unskilled labor.
} 
into account, the main quantitative result may still stay. ${ }^{15}$ For example, according to Acemoglu (2002b), the elasticity of substitution between skilled and unskilled workers is assumed to be 1.4, the degree of skill bias of technology was approximately 0.069 in 1970, and increased to 0.470 in 1990. In this circumstance, suppose that $\frac{2 \lambda+\delta-1}{2}=-\frac{2}{11}$, and that the amount of unskilled workers has increased $20 \%$ during 1970 and 1990, then (28) suggests that the growth rate in 1970 roughly equals to the one in 1990.

\subsection{Skill Premia}

Inspection of (16) yields the ratio of the wages paid for skilled workers to the ones paid for unskilled workers is

$$
\frac{w_{h}}{w_{l}}=\left(\frac{p_{h}}{p_{l}}\right)^{1 / \alpha} \cdot \frac{A_{h}}{A_{l}} .
$$

It suggests that skill premia are greater when either the relative price of the skillintensive good is higher or the technology is more skill-biased. Combining (17), (27) and (33), we obtain

$$
\frac{w_{h}}{w_{l}}=\left(\frac{A_{h}}{A_{l}}\right)^{\frac{\alpha(\epsilon-1)+\delta-1}{\alpha(\epsilon-1)}} .
$$

Obviously, $\frac{\alpha(\epsilon-1)+\delta-1}{\alpha(\epsilon-1)}$ might be positive or negative when $\epsilon>1$. Therefore, inspecting proposition 1 and (34), we state the following proposition

Proposition 3 When $\epsilon>1$ and $1-\alpha(\epsilon-1)<\delta<\frac{1}{1+\alpha(\epsilon-1)}$, skill premia increase with the amount of skilled workers; when $\epsilon>1$ and $\delta=1-\alpha(\epsilon-1)$, skill premia are unrelated to the amount of skilled workers; when $\epsilon>1$ and $\delta<1-\alpha(\epsilon-1)$, skill premia decrease with the amount of skilled workers.

Proof. See the Appendix.

An increase in the quantity of skilled workers will decrease skill premia through declining the relative price of the skill-intensive good. Obviously, the effect is determined by the elasticity of substitution between the skill-intensive and the labor-intensive good. Thus, skill premia rise with the amount of skilled workers if the effect is sufficiently weak, i.e., $\epsilon$ is great such that $1-\alpha(\epsilon-1)<\delta<\frac{1}{1+\alpha(\epsilon-1)}$ can be satisfied. Whereas, skill premia decrease if the effect is strong enough, that is, $\epsilon$ is small such that $\delta<1-\alpha(\epsilon-1)$ holds.

Since $1<1+\alpha(\epsilon-1) \leq 2,0<1-\alpha(\epsilon-1) \leq 1$. Therefore, it is remarkably possible that $1-\alpha(\epsilon-1)<\delta<\frac{1}{1+\alpha(\epsilon-1)}, \delta=1-\alpha(\epsilon-1)$ or $\delta<1-\alpha(\epsilon-1)$ hold. Thus,

\footnotetext{
${ }^{15}$ If the amount of unskilled workers also increases, then the growth rate decreases with the amount of skilled workers only when $L\left[\left(\frac{A_{h}}{A_{l}}\right)^{*}\right]^{\frac{2 \lambda+\delta-1}{2}}$ declines.
} 
proposition 3 implies that under some circumstances, even though technological change is skill-biased, skill premia may remain unchanged or decrease.

\section{International Trade, Growth and Wage Inequality}

This section investigates the impact of trade in consumer and intermediate goods on wage inequality and economic growth. We first focus on the case of trade between two identical developed countries, then consider the general case of trade between developed and developing countries. In both cases, knowledge flow with trade in intermediates is permitted.

\subsection{Trade between Identical Countries}

Because of symmetry, for simplicity and without loss of generality, we assume that the two countries develop different sets of intermediate goods in autarky. Therefore, at all points in time, there will be balanced trade. Producers of the skill-intensive good at home maximize profits, taking the price of the skill-intensive good, the prices of intermediate goods produced at home and abroad, and wages as given. That is,

$$
\begin{aligned}
\underset{k_{h}(i), k_{h}(\widehat{i})}{\max _{h}} p_{h}\left[\int_{0}^{A_{h}}\left(k_{h}(i)\right)^{1-\alpha} d i+\int_{0}^{\widehat{A}_{h}}\left(k_{h}(\widehat{i})\right)^{1-\alpha} \widehat{d i}\right] \cdot\left[H_{Y}\right]^{\alpha}-\int_{0}^{A_{h}} k_{h}(i) \chi_{h}(i) d i \\
-\int_{0}^{\widehat{A}_{h}} k_{h}(\widehat{i}) \chi_{h}(\widehat{i}) \widehat{d i}-w_{h} H_{Y}
\end{aligned}
$$

where intermediates produced at home and abroad are denoted by $i$ and $\hat{i}$, respectively. It follows from (35) that the quantities of domestic and imported intermediates are, respectively,

$$
k_{h}(i)=\left[(1-\alpha) \cdot p_{h} / \chi_{h}(i)\right]^{1 / \alpha} \cdot H_{Y} \text { and } k_{h}(\hat{i})=\left[(1-\alpha) \cdot p_{h} / \chi_{h}(\widehat{i})\right]^{1 / \alpha} \cdot H_{Y} .
$$

Equation (36) suggests that the monopoly prices of domestic and imported intermediates complementing to skills are given as $1-\alpha$. It implies that intermediates will only be exported if they are not yet invented and produced in the foreign country, and only variety not available in the domestic economy will be imported.

With similar arguments as before, we obtain

$$
k_{l}(i)=\left[(1-\alpha) \cdot p_{l} / \chi_{l}(i)\right]^{1 / \alpha} L \text { and } k_{l}(\widehat{i})=\left[(1-\alpha) \cdot p_{l} / \chi_{l}(\widehat{i})\right]^{1 / \alpha} L .
$$


Hence, the monopoly prices of domestic and imported intermediates used by unskilled workers are also $1-\alpha$. Substituting (36) and (37) into (5) and (6), respectively, we get

$$
Y_{h}=2\left(p_{h}\right)^{(1-\alpha) / \alpha} \cdot A_{h} H_{Y} \text { and } Y_{l}=2\left(p_{l}\right)^{(1-\alpha) / \alpha} \cdot A_{l} L .
$$

The combination of (4) and (38) implies (17).

Clearly, in pursuit of profits, innovation firms in the two economies will specialize in the creation of different types of intermediates. Hence, in the open world, the monopoly profits producing a type of intermediate good used by skilled workers at time $\tau$ are

$$
\pi_{h}(\tau)=2 \alpha(1-\alpha)\left[p_{h}(\tau)\right]^{1 / \alpha} \cdot H_{Y},
$$

because of symmetry. Accordingly, the monopoly profits producing a kind of intermediate good complementing unskilled workers at time $\tau$ are

$$
\pi_{l}(\tau)=2 \alpha(1-\alpha)\left[p_{l}(\tau)\right]^{1 / \alpha} \cdot L .
$$

Thus, in the equilibrium, (20), (39) and (40) suggest that the prices of skill- and labor- complementary knowledge are, respectively,

$$
P_{h}=2 \alpha(1-\alpha)\left(p_{h}\right)^{1 / \alpha} \cdot H_{Y} / r \text { and } P_{l}=2 \alpha(1-\alpha)\left(p_{l}\right)^{1 / \alpha} \cdot L / r .
$$

Since flows of knowledge are permitted between two countries, research in each country now depends on the total worldwide stock of knowledge as contained in the union of $N_{z}$ and $\widehat{N}_{z}, z=h, l$. Hence, the effective amount of knowledge that could be used in research after opening trade will be twice as large as it is before. Therefore, the knowledge accumulation equations are given by

$$
\dot{A}_{h}=2\left(A_{h}\right)^{\frac{1+\delta}{2}}\left(A_{l}\right)^{\frac{1-\delta}{2}} H_{h} \text { and } \dot{A}_{l}=2\left(A_{h}\right)^{\frac{1-\delta}{2}}\left(A_{l}\right)^{\frac{1+\delta}{2}} H_{l} .
$$

Equation (42) says that the double of effective stock of ideas has the same effect as the double of productivity in R\&D sectors.

Taking advantage of tedious algebra like Section 2, we obtain (27),

$$
H_{Y}=\frac{2 \theta H+\rho\left(A_{h} / A_{l}\right)^{\frac{1-\delta}{2}}\left[1+\left(A_{h} / A_{l}\right)^{\delta-1}\right]}{2 \theta+(1-\alpha)\left[1+\left(A_{h} / A_{l}\right)^{\delta-1}\right]},
$$

and ${ }^{16}$

\footnotetext{
${ }^{16}$ The proof of the existence of solutions to (44) is similar to the Appendix A.
} 


$$
L\left(\frac{A_{h}}{A_{l}}\right)^{\lambda}\left\{2 \theta+(1-\alpha)\left[1+\left(A_{h} / A_{l}\right)^{\delta-1}\right]\right\}-\rho\left(\frac{A_{h}}{A_{l}}\right)^{\frac{1-\delta}{2}}\left[1+\left(\frac{A_{h}}{A_{l}}\right)^{\delta-1}\right]-2 \theta H=0
$$

By (26) and (43), it is clear that free trade results in an increase in the quantity of skilled workers used in the production of the skill-intensive good. ${ }^{17}$ Therefore, we state the following proposition.

Proposition 4 When $\epsilon>1$ and $1-\alpha(\epsilon-1)<\delta<\frac{1}{1+\alpha(\epsilon-1)}$, free trade increases the degree of skill bias of technology and wage inequality. When $\lambda \geq \frac{1-\delta}{2}$, it leads to an increase in the growth rate. When $\lambda<\frac{1-\delta}{2}$, if $\left[\left(\frac{A_{h}}{A_{l}}\right)_{0}^{*} /\left(\frac{A_{h}}{A_{l}}\right)^{*}\right]^{\frac{1-2 \lambda-\delta}{2}}<2$, then it leads to an increase in the growth rate; if $\left[\left(\frac{A_{h}}{A_{l}}\right)_{o}^{*} /\left(\frac{A_{h}}{A_{l}}\right)^{*}\right]^{\frac{1-2 \lambda-\delta}{2}}=2$, then there is no change in the growth rate; if $\left[\left(\frac{A_{h}}{A_{l}}\right)_{0}^{*} /\left(\frac{A_{h}}{A_{l}}\right)^{*}\right]^{\frac{1-2 \lambda-\delta}{2}}>2$, then it results in a decrease in the growth rate, where $\left(\frac{A_{h}}{A_{l}}\right)_{0}^{*}$ is the equilibrium degree of skill bias of technology in the open economy. ${ }^{18}$

Proof. See the Appendix.

Intuitively, the double of the effective stock of ideas increases the marginal product of skilled workers, thus increasing the demand for skilled workers used in the manufacturing sector. In the meantime, the market size effect is dominant if $\epsilon>1$ and $\delta<\frac{1}{1+\alpha(\epsilon-1)}$. Therefore, trade liberalization leads to an increase in the degree of skill bias of technology. Since skill-biased technological change favors skilled workers, wage inequality goes up in the free trade regime.

Acemoglu (2003a) has shown that trade between developed and developing countries encourages technological change towards skilled workers through increasing the relative price of the skill-intensive good. Thoenig and Verdier (2003) have illustrated that free trade between developed and developing countries induces firms to adopt defensive innovation strategies, which results in an increase in the relative demand for skills, hence raising skill premia. Differently, we show that trade between developed countries raises the demand for skilled workers used in the production of the skill-intensive good, therefore inducing skill-biased technological change through the market size effect.

\footnotetext{
${ }^{17}$ Similar to the Appendix C, this can be proven easily.

${ }^{18}$ Let us briefly discuss differences between opening up to trade with a symmetric country from doubling the size of the economy. It is clear that the degree of skill bias of technology remains unchanged when the size of the economy doubles. Therefore, wage inequality in the case where a country trades with a symmetric country is larger than that in the case where the size of the country doubles. Moreover, if skill-biased technological change promotes economic growth, then the growth rate in the former case is higher than that in the latter case. In contrast, if skill-biased technological change hurts economic growth, then the growth rate in the former case is lower than that in the latter case.
} 
Some knowledge-based models (e.g., Rivera-Batiz and Romer, 1991) argue that trade with flows of ideas can permanently increase the rate of growth. However, they do not consider the direction of technological change. The paper shows, however, that skill-biased technological change may have a negative effect on economic growth. Therefore, trade opening is not always helpful to economic growth in developing countries, even though it enhances their opportunities to access advanced technology.

\subsection{Trade between Different Countries}

We now consider the general case of trade between a developed and a developing country. Suppose that the fraction of skilled workers in the developed country is higher that in the developing country, namely, $H^{N} / L^{N} \gg H^{S} / L^{S}$, where $N$ and $S$ denote the developed and the developing country, respectively.

Following Acemoglu (2003a), we assume that producers in the developing country adopt machines invented in the developed country. For convenience, we assume that the productivity of machines in the developing country is the same as the productivity in the developed country. ${ }^{19}$ In this circumstance, the demand for skill-complementary machine and the one for labor-complementary machine are, respectively,

$$
k_{h}(i)=\left[(1-\alpha) \cdot p_{h} / \chi_{h}(i)\right]^{1 / \alpha}\left(H_{Y}^{N}+H^{S}\right) \text { and } k_{l}(i)=\left[(1-\alpha) \cdot p_{l} / \chi_{l}(i)\right]^{1 / \alpha}\left(L^{N}+L^{S}\right) .
$$

Hence, the monopoly prices of intermediates are $1-\alpha$, the same as before. As a result, in the open world, the monopoly profits producing a type of intermediate good used by skilled workers at time $\tau$ are $\mathrm{a}^{20}$

$$
\pi_{h}(\tau)=\alpha(1-\alpha)\left[p_{h}(\tau)\right]^{1 / \alpha} \cdot\left(H_{Y}^{N}+H^{S}\right) .
$$

Similarly, the monopoly profits producing a kind of intermediate good complementing unskilled workers at time $\tau$ are

$$
\pi_{l}(\tau)=\alpha(1-\alpha)\left[p_{l}(\tau)\right]^{1 / \alpha} \cdot\left(L^{N}+L^{S}\right) .
$$

Thus, (20), (46) and (47) suggest that the prices of skill- and labor- complementary

\footnotetext{
${ }^{19} \mathrm{~A}$ more realistic assumption is that the productivity of machines in the developing country is proportional to that in the developed country. Main results are not altered, however.

${ }^{20}$ To simplify, we assume that R\&D firms in the developed country can capture all revenues generated by machine sales in the developing country. In the real world, due to poor property rights protection, R\&D firms in the developed country only may capture the proportion of revenues generated by machine sales in the developing country. However, the main results will be reinforced.
} 
knowledge are respectively

$$
P_{h}=\alpha(1-\alpha)\left(p_{h}\right)^{1 / \alpha} \cdot\left(H_{Y}^{N}+H^{S}\right) / r \text { and } P_{l}=\alpha(1-\alpha)\left(p_{l}\right)^{1 / \alpha} \cdot\left(L^{N}+L^{S}\right) / r .
$$

Obviously, the output of the skill-intensive good and that of the labor-intensive good in the developed country are respectively

$$
Y_{h}^{N}=\left(p_{h}\right)^{(1-\alpha) / \alpha} \cdot A_{h} H_{Y}^{N} \text { and } Y_{l}^{N}=\left(p_{l}\right)^{(1-\alpha) / \alpha} \cdot A_{l} L^{N} .
$$

Similarly, we obtain

$$
Y_{h}^{S}=\left(p_{h}\right)^{(1-\alpha) / \alpha} \cdot A_{h} H^{S} \text { and } Y_{l}^{S}=\left(p_{l}\right)^{(1-\alpha) / \alpha} \cdot A_{l} L^{S} .
$$

Combining (4), (49) and (50), we find that the relative price of the skill-intensive good

$$
p=\frac{p_{h}}{p_{l}}=\left(\frac{A_{h}}{A_{l}} \cdot \frac{H_{Y}^{N}+H^{S}}{L^{N}+L^{S}}\right)^{-\frac{\alpha}{1+\alpha(\epsilon-1)}} .
$$

Using some tedious algebra, we get

$$
\begin{gathered}
H_{Y}^{N}+H^{S}=\frac{\theta\left(H^{N}-H^{S}\right)+\rho\left(A_{h} / A_{l}\right)^{\frac{1-\delta}{2}}\left[1+\left(A_{h} / A_{l}\right)^{\delta-1}\right]}{\theta+(1-\alpha)\left[1+\left(A_{h} / A_{l}\right)^{\delta-1}\right]}, \\
\frac{A_{h}}{A_{l}}=\left(\frac{H_{Y}^{N}+H^{S}}{L^{N}+L^{S}}\right)^{\frac{1}{\lambda}}
\end{gathered}
$$

and $^{21}$

$$
\begin{aligned}
& \left(L^{N}+L^{S}\right)\left(\frac{A_{h}}{A_{l}}\right)^{\lambda}\left\{\theta+(1-\alpha)\left[1+\left(\frac{A_{h}}{A_{l}}\right)^{\delta-1}\right]\right\} \\
& -\left[\rho\left(\frac{A_{h}}{A_{l}}\right)^{\frac{1-\delta}{2}}-(1-\alpha) H^{S}\right]\left[1+\left(\frac{A_{h}}{A_{l}}\right)^{\delta-1}\right]-\theta H=0 .
\end{aligned}
$$

Using (52) and (53), we state the following proposition.

Proposition 5 Free trade decreases the degree of skill bias of technology. ${ }^{22}$ For the developed country, when $\phi>\psi$, trade leads to an increase in the growth rate; when $\phi=\psi$, the growth rate remains unchanged; whereas when $\phi<\psi$, it leads to a decreases in the growth rate, where $\phi=\left[\left(H_{Y}^{N}\right)_{o}^{*}+H^{S}\right]\left[\left(A_{h} / A_{l}\right)_{o}^{*}\right]^{\frac{\delta-1}{2}}$ and $\psi=$

\footnotetext{
${ }^{21}$ The proof of the existence of solution to (54) is similar to the Appendix A.

${ }^{22}$ Suppose that the ratio of the productivity of machines complementing $z$ in the developing country to that in the developed country is $v_{z}^{\alpha}$. Even if $v_{h}>v_{l}$, the main results are unchanged when $v_{h} H^{S}<v_{l} L^{S}$. Since developing countries are skill-scarce, $v_{h} H^{S}<v_{l} L^{S}$ is likely to be satisfied.
} 
$\left(H_{Y}^{N}\right)^{*}\left[\left(A_{h} / A_{l}\right)^{*}\right]^{\frac{\delta-1}{2}}$. For the developing country, when $\phi>\varphi$, trade leads to an increase in the growth rate; when $\phi=\varphi$, the growth rate remains invariant; whereas when $\phi<\varphi$, it leads to a decreases in the growth rate, where $\varphi=\left(H_{Y}^{S}\right)^{*}\left[\left(A_{h} / A_{l}\right)^{*}\right]^{\frac{\delta-1}{2}}$.

Proof. See the Appendix.

Due to small market of skill-complementary technology, free trade reduces the relative profits of innovation complementing skilled workers. Therefore, trade liberalization is likely to result in skill-replacing technological change. This result is different from that in Acemoglu (2003a) and Theonig and Verdier (2003) where trade induces skill-biased technological change.

With similar arguments as before, we know that international trade does not always stimulate economic growth in the developed and the developing country. Trade between developed countries, however, doubles the effective stock of ideas via knowledge flows. Therefore, open trade between developed may promote the world economic growth. Since the developing country does not usually create technology, open trade does not always increase the effective stock of ideas. As a result, open trade between the developed and developing country may decline the world growth rate.

Using some algebra, we have

$$
\left(\frac{w_{h}}{w_{l}}\right)_{o}^{*}=\left(\frac{H_{Y}^{N}+H^{S}}{L^{N}+L^{S}}\right)^{\frac{\alpha(\epsilon-1)-\lambda}{\lambda(1+\alpha(\epsilon-1))}}=\left[\left(\frac{A_{h}}{A_{l}}\right)_{o}^{*}\right]^{\frac{\alpha(\epsilon-1)+\delta-1}{\alpha(\epsilon-1)}} .
$$

Therefore, we state the following proposition

Proposition 6 When $\epsilon>1$ and $1-\alpha(\epsilon-1)<\delta<\frac{1}{1+\alpha(\epsilon-1)}$, trade leads to an increases in wage inequality in the developing country, whereas it decreases wage inequality in the developed country.

Proof. See the Appendix.

Since the degree of skill bias of technology in the opening developing country is larger than that in the developing country in the close economy, trade increases wage inequality in the developing country. In the developed country, however, owing to skill-replacing technological change, wage inequality declines.

\section{Conclusion}

We have built a knowledge-based model to explore how directed technological change impacts scale effect and skill premia, and how trade in consumer and intermediate goods influences wage inequality and economic growth. The key assumption is that $\mathrm{R} \& \mathrm{D}$ sectors use skilled workers. 
On the one hand, the average productivity of skill-complementary knowledge in the R\&D sector, which produces knowledge complementing skills, decreases with the degree of skill bias of technology. This implies that skill-biased technological change results in a decrease in the growth rate. On the other hand, the average productivity of labor-complementary knowledge in the R\&D sector, which generates labor-complementary knowledge, increases with the degree of skill bias of technology. This suggests that skill-biased technological change leads to an increase in the growth rate. Therefore, scale effect may be absent. In this paper, the two facts, accelerated skilled-biased technological change and the absence of scale effect, have been jointly accounted for in a unified framework. As far as we know, we are the first to connect skill-biased technological change and scale effect.

Free trade between developed countries increases the demand for skilled workers used in the production of the skill-intensive good, thus inducing skill-biased technological change via the market size effect. As a result, increased international trade between developed countries could be a major cause of the increase in wage inequality. On the contrary, because of small market of skill-complementary innovations in developing countries, trade between developed and developing countries may decrease their relative profits. Therefore, free trade encourages skill-replacing technological change and declines wage inequality in the developed country. However, the degree of skill bias of technology in the developing country in the open regime is greater than the one before opening, therefore trade leads to an increase in skill premia in the developing country.

Since the degree of skill bias of technology has opposite effects on economic growth, free trade promotes economic growth under some circumstances and hinders economic growth under other circumstances. This implies that trade opening does not always promote economic growth in developing countries, even though it increases their opportunities to access advanced technology. 


\section{References}

[1] Acemoglu, Daron, 1998, "Why Do New Technologies Complement Skills? Directed Technical Change and Wage Inequality", Quarterly Journal of Economics, 113, 1055-1090.

[2] Acemoglu, Daron and Fabrizio Zilibotti, 2001, "Productivity Difference", Quarterly Journal of Economics, 116, 563-606.

[3] Acemoglu, Daron, 2002a, "Directed Technical Change", Review of Economic Studies, 69, 781-809.

[4] Acemoglu, Daron, 2002b, "Technical Change, Inequality, and the Labor Market", Journal of Economic Literature, 40, 7-72.

[5] Acemoglu, Daron, 2003a, "Patterns of Skill Premia", Review of Economic Studies, 70, 199230 .

[6] Acemoglu, Daron, 2003b, "Cross-country Inequality Trends", Economic Journal, 113, F121F149.

[7] Acemoglu, Daron, 2007, "Equilibrium Bias of Technology", Econometrica, 75, 1371-1409.

[8] Acemoglu, Daron, 2009, Introduction to Modern Economic Growth, Princeton: Princeton University Press, 2009.

[9] Aghion, Philippe and Peter Howitt, "A Model of Growth through Creative Destruction", Econometrica, 1992, 60, 323-351.

[10] Aghion, Philippe and Peter Howitt, Endogenous Growth Theory, Cambridge, MA: MIT Press, 1998.

[11] Aghion, Philippe, Eve Carloli and Cecilia Garcí-Peñalosa, 1999, "Inequality and Economic Growth: The Perspective of the New Growth Theories", Journal of Economic Literature, $37,1615-1660$.

[12] Autor, David, Alan Krueger and Lawrence Katz, 1998, "Computing Inequality: Have Computers Changed the Labor Market?", Quarterly Journal of Economics, 113, 1169-213.

[13] Dinopoulos, Elias and Peter Thompson, 1998, "Schumpeterian Growth without Scale Effects", Journal of Economic Growth, 313-335.

[14] Feenstra, R.C., 1998, "Integration of Trade and Disintegration of Production in the Global Economy", Journal of Economic Perspectives, 12, 31-50.

[15] Feenstra, R.C., and G.H. Hanson, 1996, "Globalization, Outsourcing and Wage Inequality", American Economic Review, 86, 240-245. 
[16] Hornsteiny, Andreas, Per Krusellz Giovanni and L. Violante, "The Effects of Technical Change on Labor Market Inequalities", in Philippe Aghion and Steven Durlauf, eds., Handbook of Economic Growth, Amsterdam: Elsevier, 2005.

[17] Grossman, Gene M. and Elhanan Helpman, Innovation and Growth in the Global Economy, Cambridge, MA: MIT Press, 1991.

[18] Jones, Charles, 1995a, "R\&D-based Models of Economic Growth", Journal of Political Economy, 103, 759-784.

[19] Jones, Charles, 1995b, "Time Series Tests of Endogenous Growth Models", Quarterly Journal of Economics, 110, 495-525.

[20] Jones, Charles, 1999, "Growth: With or without Scale Effect?", American Economic Review, 89, 139-144.

[21] Jones, Charles, "Growth and Ideas", in Philippe Aghion and Steven Durlauf, eds., Handbook of Economic Growth, Amsterdam: Elsevier, 2005.

[22] Katz, L. and K. Murphy, 1992, "Changes in Relative Wages, 1963-1987: Supply and Demand Factors", Quarterly Journal of Economics, 107, 35-78.

[23] Kortum, Samuel, 1997, "Research, Patenting, and Technological Growth", Econometrica, 65, 1389-1419.

[24] Krugman, P.R., 1995, "Growing World Trade: Causes and Consequences", Brookings Papers on Economic Activity, 1, 327-377.

[25] Krugman, P.R., 2000, "Technology, Trade and Factor Prices", Journal of International Economics, 50, 51-71.

[26] Krusell, P., L. Ohanian, J.-V. Rios-Rull and G.L. Violante, 2000, "Capital Skill Complementarity and Inequality: A Macroeconomic Analysis", Econometrica, 68, 1029-1053.

[27] Laincz, Christopher and Pietro Peretto, 2006, "Scale Effects in Endogenous Growth Theory: An Error of Aggregation not Specification", Journal of Economic Growth, 11, 263-288.

[28] Peretto, Pietro, 1998, "Technological Change and Population Growth", Journal of Economic Growth, 3, 283-311.

[29] Peretto, Pietro and Sjak Smulders, 2002, "Technological Distance, Growth and Scale Effects", Economic Journal, 112, 603-624.

[30] Rivera-Batiz, Luis A. and Paul M. Romer, 1991, "Economic Integration and Endogenous Growth", Quarterly Journal of Economics, 106, 531-555. 
[31] Romer, Paul M., 1990, "Endogenous Technological Change", Journal of Political Economy, 98, s71-s102.

[32] Segerstrom, Paul, 1998, "Endogenous Growth Without Scale Effects", American Economic Review, 88, 1290-1310.

[33] Thoenig, Mathias and Thierry Verdier, 2003, "A Theory of Defensive Skill-Biased Innovation and Globalization", American Economic Review, 93, 709-728.

[34] Young, Alwyn, 1998, "Growth Without Scale Effects", Journal of Political Economy, 106, 41-63. 


\section{Appendix A: Existence of the Solutions}

Equation (28) implies that $f(+\infty)=+\infty, f(0)=-\infty$ as $\lambda>\frac{1-\delta}{2}$, and $f(+\infty)=-\infty$, $f(0)=+\infty$ as $\lambda<\frac{1-\delta}{2}$. In the meantime, $f(\cdot)$ is continuous. Therefore, there exists at least one solution to (28) when $\lambda \neq \frac{1-\delta}{2}$. In addition, when $\lambda=\frac{1-\delta}{2},(28)$ can be rewritten as $\left(A_{h} / A_{l}\right)^{2 \lambda}[(1+\theta-\alpha) L-\rho]-\theta H\left(A_{h} / A_{l}\right)^{\lambda}+(1-\alpha) L-\rho=0$. Hence, when $(1+\theta-\alpha) L-\rho \neq 0$ and $\theta^{2} H^{2}-4[(1+\theta-\alpha) L-\rho] \cdot[(1-\alpha) L-\rho] \geq 0$, there exists at least one solution to (28).

\section{Appendix B: The Number of the Solutions to (28)}

When $\delta=1,(28)$ is

$$
f\left(\frac{A_{h}}{A_{l}}\right)=[\theta+2(1-\alpha)] L\left(\frac{A_{h}}{A_{l}}\right)^{\lambda}-2 \rho-\theta H=0 .
$$

It has the unique solution $\frac{A_{h}}{A_{l}}=\left(\frac{2 \rho+\theta H}{\theta L+2(1-\alpha) L}\right)^{\frac{1}{\lambda}}$.

In the following, we assume that $\delta \neq 1$. Denoting $x=\left(\frac{A_{h}}{A_{l}}\right)^{\frac{1-\delta}{2}},(28)$ is changed to be

$$
F(x) \triangleq f\left(x^{\frac{2}{1-\delta}}\right)=(\theta L+a) x^{m}+a x^{m-2}-\rho x-\rho x^{-1}-\theta H=0,
$$

where $0 \leq x<+\infty, a=(1-\alpha) L$ and $m=\frac{2 \lambda}{1-\delta}$. Simple calculus gives

$$
\begin{gathered}
F_{1}(x) \triangleq x^{2} F^{\prime}(x)=m(\theta L+\alpha) x^{m+1}+(m-2) a x^{m-1}-\rho x^{2}+\rho, \\
F_{2}(x) \triangleq F_{1}^{\prime}(x)=m(m+1)(\theta L+\alpha) x^{m}+(m-2)(m-1) a x^{m-2}-2 \rho x, \\
F_{3}(x) \triangleq F_{2}^{\prime}(x)=m^{2}(m+1)(\theta L+a) x^{m-1}+(m-2)^{2}(m-1) a x^{m-3}-2 \rho,
\end{gathered}
$$

and

$$
F_{4}(x) \triangleq F_{3}^{\prime}(x)=(m-1) m^{2}(m+1)(\theta L+a) x^{m-2}+(m-3)(m-2)^{2}(m-1) a x^{m-4} .
$$

These formulas clarify completely the properties of solutions to (A1). Firstly, for $m=1$,

$$
F(x)=(\theta L+a-\rho) x+(a-\rho) x^{-1}-\theta H .
$$

- If $a>\rho, F(0)=F(+\infty)=+\infty$ and $F(x)$ arrives at its minimum at $x=\left(\frac{a-\rho}{\theta L+a-\rho}\right)^{\frac{1}{2}}$. Hence

- (A1) has two solutions when the minimum is negative;

- (A1) has only one solution when the minimum is zero; 
- (A1) has no solution when the minimum is positive.

- If $\theta L+a<\rho, F(0)=F(+\infty)=-\infty$ and $F(x)$ arrives at its maximum at $x=$ $\left(\frac{a-\rho}{\theta L+a-\rho}\right)^{\frac{1}{2}}$. Hence

- (A1) has two solutions when the maximum is positive;

- (A1) has only one solution when the maximum is zero;

- (A1) has no solution when the maximum is negative.

- If $\theta L+a>\rho>a, F(0)=-\infty, F(+\infty)=+\infty$ and $F^{\prime}(x)>0$. Hence (A1) is uniquely solved.

- If $\theta L+a=\rho>a$, there is no solution.

- If $\theta L+a>\rho=a$, the unique solution is $x=\frac{H}{L}$.

Since $F(0)=-\infty$ and $F(+\infty)=+\infty$ if $m>1$, and $F(0)=+\infty$ and $F(+\infty)=-\infty$ if $m<1$, there exists at least one solution to (A1) for $m \neq 1$. By analyzing functions $F_{1}, F_{2}, F_{3}$ and $F_{4}$, we can show clearly the number of the solutions. For instance, we provide some qualitative conclusions as follows.

- $m \geq 3: F_{4}(x)>0$, and therefore $F_{3}(x)$ strictly increases. Since $F_{3}(0)=-2 \rho$ and $F_{3}(+\infty)=+\infty, F_{3}(x)=0$ is uniquely solved. Moreover, $F_{2}(x)$ decreases before increasing. Now that $F_{2}(0)=0$ implies that $F_{2}(x)=0$ has two solutions (one is zero and the other is supposed as $\left.x_{1}>0\right)$. Consequently, $F_{1}(x)$ is also decreases before increasing, and $F_{1}(0)=\rho$ and $F_{1}(+\infty)=+\infty$ imply that

- (A1) has only one solution, if $F_{1}\left(x_{1}\right) \geq 0$, which means that $F(x)$ is strictly increasing;

- The number of solutions to (A1) may be 1,2 , or 3 , if $F_{1}\left(x_{1}\right)<0$, which means that $F(x)$ is a strictly increasing-decreasing-increasing function.

- $2<m<3: F_{4}(x)$ is strictly increasing and has only one zero point (supposed to be $\left.x_{2}>0\right)$. Thus $F_{3}(x)$ is strictly decreasing-increasing, and from $F_{3}(0)=+\infty$ and $F_{3}(+\infty)=+\infty$, we get that the solutions of $F_{3}(x)=0$ depend on its minimum, i.e. $F_{3}\left(x_{2}\right)$. Generally, $F_{3}(x)$ may have 0,1 or 2 zero points. Therefore, $F_{2}(x)$ maybe strictly increasing, or increasing-decreasing-increasing. Now that $F_{2}(0)=0$ and $F_{2}(+\infty)=+\infty$ imply that $F_{2}(x)=0$ may have 1 (precisely $x=0$ ), 2 (one is zero and the other is positive), or 3 (the last supposed to be $x_{3}>0$ ) solutions. The former two cases suggest that $F_{1}(x)$ is strictly increasing, and the latter suggests that $F_{1}(x)$ is increasing-decreasing-increasing. Hence $F_{1}(0)=\rho$ and $F_{1}(+\infty)=+\infty$ imply that 
- (A1) has only one solution, if $F_{1}\left(x_{3}\right) \geq 0$, which means that $F(x)$ is strictly increasing;

- The number of solutions to (A1) may be 1,2 , or 3 , if $F_{1}\left(x_{3}\right)<0$, which means that $F(x)$ is an increasing-decreasing-increasing function.

- $m=2: F_{4}(x)>0$, and therefore $F_{3}(x)$ strictly increases. Since $F_{3}(0)=-2 \rho$ and $F_{3}(+\infty)=+\infty, F_{3}(x)=0$ is uniquely solved, and then $F_{2}(x)$ is strictly decreasing-increasing. Now that $F_{2}(0)=0$ implies that $F_{2}(x)=0$ has two solutions (one is zero and the other is supposed as $x_{4}>0$ ). As a result, $F_{1}(x)$ is also strictly decreasing-increasing, and $F_{1}(0)=\rho$ and $F_{1}(+\infty)=+\infty$ imply that

- (A1) has only one solution, if $F_{1}\left(x_{4}\right) \geq 0$, which means that $F(x)$ is strictly increasing;

- The number of solutions to (A1) may be 1,2 , or 3 , if $F_{1}\left(x_{4}\right)<0$, which means that $F(x)$ is a strictly increasing-decreasing-increasing function.

- $1<m<2: F_{4}(x)=0$ is uniquely solved at $x_{5}>0, F_{4}(x)<0$ for $x<x_{5}$ and $F_{4}(x)>$ 0 for $x>x_{5}$. In fact, $F_{4}(x)$ increases from $-\infty$ to its positive maximum and then decreases to 0 . Now $F_{3}(x)$ is strictly decreasing-increasing from $F_{3}(0)=+\infty$ to $F_{3}(+\infty)=+\infty$. Thus the solutions of $F_{3}(x)=0$ depend on its minimum, i.e. $F_{3}\left(x_{5}\right)$. Generally, $F_{3}(x)$ may have 0,1 or 2 zero points. Therefore, $F_{2}(x)$ maybe strictly increasing, or increasing-decreasing-increasing. Since $F_{2}(0)=-\infty$ and $F_{2}(+\infty)=+\infty$, we have $F_{2}(x)=0$ may have 1,2 , or 3 positive solutions. The former two cases assure that $F_{1}(x)$ is strictly decreasing-increasing, and the latter assure that $F_{1}(x)$ is strictly decreasing-increasing-decreasing-increasing. Therefore $F_{1}(0)=\rho$ and $F_{1}(+\infty)=+\infty$ imply that

- (A1) has only one solution, if the minimum of $F_{1}(x)$ is nonnegative;

- The number of solutions to (A1) may be 1,2 , or 3 , if the negative minimum of $F_{1}(x)$ is reached at only one minimal point;

- The number of solutions to (A1) may be 1,2 , or 3 , if the local maximum of $F_{1}(x)$ is non-positive;

- The number of solutions to (A1) may be $1,2,3,4$, or 5 , if the negative local minimums of $F_{1}(x)$ is reached at two minimal points and the local maximum is positive.

- $m<1: F_{4}(x)=0$ is uniquely solved at $x_{6}>0, F_{4}(x)>0$ for $x<x_{6}$ and $F_{4}(x)<0$ for $x>x_{6}$. In fact, $F_{4}(x)$ decrease from $+\infty$ to its negative minimum and then increases to 0 . Now $F_{3}(x)$ is strictly increasing-decreasing from $F_{3}(0)=-\infty$ to 
$F_{3}(+\infty)=-2 \rho$. Thus the solutions of $F_{3}(x)=0$ depend on its maximum, i.e. $F_{3}\left(x_{6}\right)$. Generally, $F_{3}(x)$ may have 0,1 or 2 zero points. Therefore, $F_{2}(x)$ may be strictly decreasing, or decreasing-increasing-decreasing. Since $F_{2}(0)=+\infty$ and $F_{2}(+\infty)=-\infty$, we have $F_{2}(x)=0$ may have 1 , 2 , or 3 positive solutions. The former two cases assure that $F_{1}(x)$ is strictly increasing-decreasing, and the latter assure that $F_{1}(x)$ is increasing-decreasing-increasing-decreasing. Therefore, $F_{1}(0)=-\infty$ and $F_{1}(+\infty)=-\infty$ imply that

- (A1) has only one solution, if the maximum of $F_{1}(x)$ is non-positive;

- The number of solutions to (A1) may be 1,2 , or 3 , if the positive maximum of $F_{1}(x)$ is reached at only one maximal point;

- The number of solutions to (A1) may be 1,2 , or 3 , if the local minimum of $F_{1}(x)$ is nonnegative;

- The number of solutions to (A1) may be $1,2,3,4$, or 5 , if the positive local maximums of $F_{1}(x)$ is reached at two maximal points and the local minimum is negative.

Appendix C: $\frac{\partial\left(H_{Y} / L\right)}{\partial(H / L)}>0$

Inspection of (26) gives

$$
\begin{aligned}
& \frac{\partial H_{Y}}{\partial H}= \frac{\left\{\theta+(1-\alpha)\left[1+\left(\frac{H_{Y}}{L}\right)^{\frac{\delta-1}{\lambda}}\right]\right\}\left\{\theta \lambda L+\frac{\rho(1-\delta)}{2}\left(\frac{H_{Y}}{L}\right)^{\frac{-\delta-1}{2 \lambda}}\left[1+\left(\frac{H_{Y}}{L}\right)^{\frac{\delta-1}{\lambda}}\right]\left(\frac{H_{Y}}{L}\right)^{\frac{1-\lambda}{\lambda}} \frac{\partial H_{Y}}{\partial H}\right\}}{\lambda L\left\{\theta+(1-\alpha)\left[1+\left(\frac{H_{Y}}{L}\right)^{\frac{\delta-1}{\lambda}}\right]\right\}^{2}} \\
&+\frac{(1-\delta)\left(\frac{H_{Y}}{L}\right)^{\frac{\delta-2}{\lambda}}\left[\theta(1-\alpha) H-\rho \theta\left(\frac{H_{Y}}{L}\right)^{\frac{1-\delta}{2 \lambda}}\right]\left(\frac{H_{Y}}{L}\right)^{\frac{1-\lambda}{\lambda}} \frac{\partial H_{Y}}{\partial H}}{\lambda L\left\{\theta+(1-\alpha)\left[1+\left(\frac{H_{Y}}{L}\right)^{\frac{\delta-1}{\lambda}}\right]\right\}^{2}}
\end{aligned}
$$

It suggests $\frac{\partial H_{Y}}{\partial H} \neq 0$. Equations (27) and (29) imply that when $\lambda \geq \frac{\delta}{2}, \frac{\partial H_{Y}}{\partial H}>0$. Otherwise, consumers would like to raise both $H_{Y}$ and $g$ to increase utility as $H$ enlarges. They also imply that when $\lambda<\frac{\delta}{2}$, if $\frac{\partial H_{Y}}{\partial H}<0$, then $\frac{\partial g}{\partial H}>0$. Clearly, all other things being equal, a decrease in $H_{Y}$ reduces the aggregate output, therefore declining social welfare. Consequently, when $H$ increases, a decrease in $H_{Y}$ and an increase in $g$ is not optimal for consumers who prefer smoothing consumption. As a result, $H_{Y}$ goes up such that $\frac{\partial H_{Y}}{\partial H}>0$ and $\frac{\partial g}{\partial H}<0$ hold.

It is clear that when $H, L$ increase and $H / L$ remains invariant, $H_{Y} / L$ remains unchanged in the equilibrium. Therefore, when $H, L$ and $H / L$ increase, $H_{Y} / L$ raises 
in the equilibrium. Similar arguments yields that when $H, L$ decreases but $H / L$ raises, $H_{Y} / L$ also enlarges in the equilibrium. Therefore, $\frac{\partial\left(H_{Y} / L\right)}{\partial(H / L)}>0$.

\section{Appendix D: Proof of Propositions}

Proof of Proposition 1: By (27), we have

$$
\frac{\partial\left(A_{h} / A_{l}\right)}{\partial(H / L)}=\frac{1}{\lambda}\left(\frac{A_{h}}{A_{l}}\right)^{1-\lambda} \cdot \frac{\partial\left(H_{Y} / L\right)}{\partial(H / L)} .
$$

Obviously, when $\epsilon>1$ and $\delta<\frac{1}{1+\alpha(\epsilon-1)}, \lambda>0$. Hence, $\frac{\partial\left(A_{h} / A_{l}\right)}{\partial(H / L)}>0$, that is, technological change is skill-biased.

Proof of Proposition 2: It is obvious from proposition 1 and (29).

Proof of Proposition 3: It is clear from proposition 1 and (34).

Proof of Proposition 4: Free trade leads to an increase in the quantity of skilled workers used in the production of the skill-intensive good, hence when $\epsilon>1$ and $\delta<\frac{1}{1+\alpha(\epsilon-1)}$ hold, open trade increases the degree of skill bias of technology and wage inequality.

Obviously, the growth rate in the open economy is

$$
g_{o}^{*}=\frac{2(1-\alpha) L\left[\left(\frac{A_{h}}{A_{l}}\right)_{o}^{*}\right]^{\frac{2 \lambda+\delta-1}{2}}-\rho}{\theta} .
$$

Therefore, when $\lambda>\frac{1-\delta}{2}$ and $\lambda=\frac{1-\delta}{2}$, the growth rate goes up. When $\lambda<\frac{1-\delta}{2}$, if $\left[\left(\frac{A_{h}}{A_{l}}\right)_{o}^{*} /\left(\frac{A_{h}}{A_{l}}\right)^{*}\right]^{\frac{1-2 \lambda-\delta}{2}}<2$, the growth rate raises; if $\left[\left(\frac{A_{h}}{A_{l}}\right)_{o}^{*} /\left(\frac{A_{h}}{A_{l}}\right)^{*}\right]^{\frac{1-2 \lambda-\delta}{2}}=2$, the growth rate remains unchanged; if $\left[\left(\frac{A_{h}}{A_{l}}\right)_{0}^{*} /\left(\frac{A_{h}}{A_{l}}\right)^{*}\right]^{\frac{1-2 \lambda-\delta}{2}}>2$, the growth rate decreases.

Proof of Proposition 5: Combination of (52), (53) and Appendix C implies that international trade leads to $\left(\frac{A_{h}}{A_{l}}\right)_{o}^{*}<\left(\frac{A_{h}}{A_{l}}\right)^{*}$. That is, free trade may encourage skill-replacing technological change. Now the growth rate in the open economy is

$$
g_{o}^{*}=\frac{(1-\alpha)\left[\left(H_{Y}^{N}\right)_{o}^{*}+H^{S}\right]\left[\left(\frac{A_{h}}{A_{l}}\right)_{o}^{*}\right]^{\frac{\delta-1}{2}}-\rho}{\theta} .
$$

Therefore, for the developed country, when $\phi>\psi$, trade increases the growth rate; when $\phi=\psi$, the growth rate remains invariant; whereas when $\phi<\psi$, it decreases the growth rate. For the developing country, when $\phi>\varphi$, trade leads to an increase 
in the growth rate; when $\phi=\varphi$, the growth rate remains invariant; whereas when $\phi<\varphi$, it leads to a decreases in the growth rate.

Proof of Proposition 6: Obviously, before trade liberalization, skill premia in the developed and the developing country are

$$
\left(\frac{w_{h}}{w_{l}}\right)^{N}=\left[\left(\frac{A_{h}}{A_{l}}\right)^{N *}\right]^{\frac{\alpha(\epsilon-1)+\delta-1}{\alpha(\epsilon-1)}} \text { and }\left(\frac{w_{h}}{w_{l}}\right)^{S}=\left[\left(\frac{A_{h}}{A_{l}}\right)^{S *}\right]^{\frac{\alpha(\epsilon-1)+\delta-1}{\alpha(\epsilon-1)}} .
$$

Since $\epsilon>1$ and $1-\alpha(\epsilon-1)<\delta<\frac{1}{1+\alpha(\epsilon-1)}, \alpha(\epsilon-1)-\lambda>0$. Proposition 5 suggests that $\left(\frac{A_{h}}{A_{l}}\right)^{N *}>\left(\frac{A_{h}}{A_{l}}\right)_{o}^{*}$, therefore wage inequality declines in the developed country. In the meantime, becuase of $H^{N} / L^{N} \gg H^{S} / L^{S},(52),(53)$ and Appendix $\mathrm{C}$ together with the results in Section 3 imply that $\left(\frac{A_{h}}{A_{l}}\right)^{S *}<\left(\frac{A_{h}}{A_{l}}\right)_{0}^{*}$. It follows that wage inequality increases in the developing country. 